\title{
New-onset diabetes after adult liver transplantation in the Korean Organ Transplantation Registry (KOTRY) study
}

\author{
Jong Man Kim ${ }^{1}$, Shin Hwang ${ }^{2}$, Kwang-Woong Lee ${ }^{3}$, Jae-Geun Lee ${ }^{4}$, Je Ho Ryu ${ }^{5}$, Bong-Wan Kim ${ }^{6}$, \\ Dong Lak Choi ${ }^{7}$, Young Kyoung You ${ }^{8}$, Dong-Sik Kim ${ }^{9}$, Yang Won Nah ${ }^{10}$, Koo Jeong Kang ${ }^{11}$, \\ Jai Young Cho ${ }^{12}$, Geun Hong ${ }^{13}$, In Seok Choi ${ }^{14}$, Hee Chul Yu ${ }^{15}$, Dongho Choi ${ }^{16}$, Myoung Soo Kim ${ }^{4}$; \\ The Korean Organ Transplantation Registry Study Group
}

${ }^{1}$ Department of Surgery, Samsung Medical Center, Sungkyunkwan University School of Medicine, Seoul, South Korea; ${ }^{2}$ Department of Surgery, Asan Medical Center, College of Medicine University of Ulsan, South Korea; ${ }^{3}$ Department of Surgery, Seoul National University College of Medicine, Seoul, South Korea; ${ }^{4}$ Department of Surgery, Yonsei University College of Medicine, Seoul, South Korea; ${ }^{5}$ Department of Surgery, Pusan National University College of Medicine, Busan, South Korea; ${ }^{6}$ Department of Liver Transplantation and Hepatobiliary Surgery, Ajou University School of Medicine, Suwon, South Korea; ${ }^{7}$ Department of Surgery, Catholic University of Daegu College of Medicine, Daegu, South Korea; ${ }^{8}$ Department of Surgery, College of Medicine, Catholic University of Korea, Seoul, South Korea; ${ }^{9}$ Division of HBP Surgery and Liver Transplantation, Department of Surgery, Korea University College of Medicine, Seoul, South Korea; ${ }^{10}$ Department of Surgery, Ulsan University Hospital, University of Ulsan College of Medicine, Ulsan, South Korea; ${ }^{11}$ Department of Surgery, Keimyung University School of Medicine, Daegu, South Korea; ${ }^{12}$ Department of Surgery, Seoul National University Bundang Hospital, Seoul National University College of Medicine, Sungnam, South Korea; ${ }^{13}$ Department of Surgery, Ewha Woman's University School of Medicine, Seoul, South Korea; ${ }^{14}$ Department of Surgery, Konyang University Hospital, Daejon, South Korea; ${ }^{15}$ Department of Surgery, Chonbuk National University School of Medicine, Jeonju, South Korea; ${ }^{16}$ Department of Surgery, Hanyang University College of Medicine, Seoul, South Korea

Contributions: (I) Conception and design: JM Kim; (II) Administrative support: None; (III) Provision of study materials or patients: None; (IV) Collection and assembly of data: JM Kim, MS Kim, S Hwang, KW Lee, JG Lee, JH Ryu, BW Kim, DL Choi, YK You, DS Kim, YW Nah, KJ Kang, JY Cho, G Hong, IS Choi, HC Yu, D Choi; (V) Data analysis and interpretation: JM Kim, MS Kim, S Hwang, KW Lee, JG Lee; (VI) Manuscript writing: All authors; (VII) Final approval of manuscript: All authors.

Correspondence to: Prof. Myoung Soo Kim, MD, PhD. Department of Surgery, Yonsei University College of Medicine, 50 Yonsei-ro, Seodaemun-gu, Seoul 03722, South Korea. Email: ysms91@yuhs.ac.

Background: New-onset diabetes after transplantation (NODAT) is a serious complication following liver transplantation (LT). The present study aimed to investigate the incidence of and risk factors for NODAT using the Korean Organ Transplantation Registry (KOTRY) database.

Methods: Patients with history of pediatric transplantation (age $\leq 18$ years), re-transplantation, multi-organ transplantation, or pre-existing diabetes mellitus were excluded. A total of 1,919 non-diabetic adult patients who underwent a primary LT between May 2014 and December 2017 were included. Risk factors were identified using Cox regression analysis.

Results: NODAT occurred in $19.7 \%$ ( $n=377$ ) of adult liver transplant recipients. Multivariate analysis showed steroid use, increased age, and high body mass index (BMI) in recipients, and implantation of a leftside liver graft was closely associated with NODAT in adult LT. In living donor liver transplant (LDLT) patients $(\mathrm{n}=1,473)$, open donor hepatectomy in the living donors, steroid use, small for size liver graft (graft to recipient weight ratio $\leq 0.8$ ), increased age, and high $\mathrm{BMI}$ in the recipient were predictive factors for NODAT. The use of antimetabolite and basiliximab induction reduced the incidence of NODAT in adult LT and in adult LDLT.

Conclusions: Basiliximab induction, early steroid withdrawal, and antimetabolite therapy may prevent NODAT after adult LT. High BMI or advanced age in liver recipients, open donor hepatectomy in living donors, and small size liver graft can predict the occurrence of NODAT after adult LT or LDLT.

Keywords: Diabetes; living donors; immunosuppression; Asia 
Submitted May 26, 2019. Accepted for publication Aug 05, 2019.

doi: $10.21037 /$ hbsn.2019.10.29

View this article at: http://dx.doi.org/10.21037/hbsn.2019.10.29

\section{Introduction}

Advancements in surgical techniques for liver transplantation (LT), optimization of immunosuppressive regimens and perioperative monitoring methods are improving the survival of LT recipients. Thus, key post-transplant concerns are now long-term complications and quality of life after LT as opposed to short-term complications and perioperative mortality in the past.

New-onset diabetes after transplantation (NODAT) is currently the most common postoperative metabolic complication after LT (1). NODAT refers to the development of post-transplant diabetes in previously non-diabetic patients (i.e., patients who are not diabetic before transplantation, but show sustained high blood glucose levels after transplantation and meet the World Health Organization diagnostic criteria for diabetes). The development of NODAT is closely associated with acute rejection, infection, chronic cardiovascular disease, chronic renal insufficiency and decreased graft survival, all of which are leading causes of mortality among LT recipients (2-10). In addition, patients who develop NODAT have increased health care costs $(1,2,11)$. However, the mechanisms underlying NODAT after LT has not been investigated extensively and NODAT after LT has received less attention compared to NODAT after kidney transplantation. NODAT is a serious complication of LT that negatively affects patients' health and graft survival. The reported incidence of NODAT after LT ranges from $9 \%$ to $63.3 \%(5)$.

Multiple risk factors for NODAT in liver transplant recipients have been reported: increased recipient age, African-American ethnicity, hepatitis $\mathrm{C}$ virus (HCV) infection, advanced liver cirrhosis, liver graft from deceased donor, tacrolimus use, alcoholic liver disease, steroid use, high body mass index (BMI), hypomagnesemia, biopsy-proven acute rejection, and cytomegalovirus infection $(1,5,9,12)$.

Studies based on national registries and other administrative datasets have made enormous contributions to the science of organ transplantation. The Korean Organ Transplantation Registry (KOTRY) is a nationwide prospective cohort designed to play an academically oriented role beyond that of just an administrative registry. The KOTRY compiles and analyzes at regular intervals demographic and clinical information of new liver transplant patients and donors, as well as data on the use of immunosuppressive drugs, post-operative outcomes and other endpoints $(13,14)$. In 2015, there were 44 liver transplant centers in Korea, among which 15 participated in the KOTRY. Due to a high number of large-volume centers joining the KOTRY, $77.1 \%$ of LT performed annually were enrolled in the KOTRY database.

Data regarding the risk factors, incidence, and clinical consequences of NODAT in Korean liver transplant recipients are lacking. Nearly $70 \%$ of liver transplants recorded in the KOTRY have been from living donors; the risk factors for NODAT in KOTRY are likely to be inconsistent with the risk factors identified in studies based on deceased donor liver transplantation (DDLT) $(1,2,12)$. Using the KOTRY database, we aimed to investigate the occurrence of NODAT in South Korea, to evaluate its impact on prognosis of graft survival and identify possible risk factors for NODAT. We present the following article in accordance with the STROBE reporting checklist (available at http://dx.doi.org/10.21037/hbsn.2019.10.29).

\section{Methods}

\section{Patients}

The study population comprised of patients who underwent LT between April 2014 and December 2017 $(n=2,648)$. The KOTRY organizational structure, patient enrollment and informed consent have been described in previous reports $(15,16)$. Patients with history of pediatric transplantation (age $\leq 18$ years), re-transplantation, multiorgan transplantation, or pre-existing diabetes mellitus were excluded. A total of 1,919 patients without preexisting diabetes were included in the final study cohort. Both donors and recipients were required to register with the KOTRY before transplantation. All registered patients were routinely followed up at their outpatient clinic. This study was approved by the KOTRY, which is the only authorized national LT registry in South Korea. The study was initiated after obtaining approval from the ethics committee for each participating center, according to the Regulations on Human Organ Transplant and national legal 
requirements. The procedures were in accordance with the Helsinki declaration. All patients provided informed consent prior to participation in the study.

\section{Definition of NODAT}

The presence of diabetes as a co-morbid condition prior to transplantation was identified by querying the KOTRY database entries for our patient population. NODAT was defined using the American Diabetes Association (ADA) diagnostic criteria: an fating plasma glucose level $\geq 126 \mathrm{mg} / \mathrm{dL}(7.0 \mathrm{mmol} / \mathrm{L})$, symptoms of polyuria, polydipsia and/or unexplained weight loss, a random plasma glucose concentration of $\geq 200 \mathrm{mg} / \mathrm{dL}$, and an HbA1c value of $\geq 6.5 \%$ (17). Fasting was defined as no caloric intake for at least 8 hours. Glomerular filtration rate (GFR) was calculated using the MDRD equation (18). CKD in the post-transplant was defined as more than stage 3 (GFR $<60 \mathrm{~mL} / \mathrm{min}$ ).

The presence of NODAT was identified in the previously non-diabetic transplant recipients when at least one record of diabetes was entered in the follow-up reports after LT. If diabetes disappeared after steroid withdrawal or 6 months in the post-transplant, we did not define NODAT case in those patients. The date of onset of NODAT was assumed to be the date of the earliest report of diabetes after liver transplant.

\section{Data collection in recipients and donors, and transplant- related factors}

We assessed the following recipient-related risk factors; gender, age, history of hypertension, pre-transplant BMI $\left(\mathrm{kg} / \mathrm{m}^{2}\right)$, primary liver disease, hepatocellular carcinoma (HCC), Child-Pugh class, Model for End-stage Liver Disease (MELD) scores for chronic liver disease or cirrhosis, urgent status in Korean Network for Organ Sharing (KONOS), and serum creatinine levels at 1 month, 6 months, 1 year, 2 years, and 3 years. Donor-related factors included donor gender, presence of hypertension or diabetes, and BMI. Transplant-related factors included LT type (DDLT or LDLT), ABO-incompatibility, liver graft (whole liver, left-side liver graft, or right-side liver graft), macrosteatosis in the donor liver, living related donor, surgical approach in living liver donor (open or minimal invasive approach, including laparoscopic or robotic donor hepatectomy), small size liver graft [graft to recipient weight ratio $(\mathrm{GRWR}) \leq 0.8$ ], hospitalization after $\mathrm{LT}$, basiliximab induction, selection of calcineurin inhibitors (tacrolimus or cyclosporine) at discharge, use of antimetabolite (mycophenolate mofetil or mycophenolic acid) or steroid at discharge, and use of mTOR inhibitors at 6 months.

The current KONOS system utilizes an urgent DDLT allocation system for adult patients similar to that used by the previous United Network for Organ Sharing (UNOS) system. UNOS status 1 including early retransplantation and status $2 \mathrm{~A}$ categories are identical to KONOS status 1 and status 2A, respectively (19). Patients with known hepatitis $\mathrm{B}$ virus (HBV) infection cannot be KONOS status 1 due to the high prevalence of $\mathrm{HBV}$ in Korea and difficulty in discerning acute liver failure from acute-on-chronic liver failure in these patients.

\section{Statistical analysis}

Continuous data are expressed as the mean \pm SD. Statistical comparisons were made using independent $t$-tests for normally distributed data. Continuous variables, including donor and recipient BMI, MELD score, and macrosteatosis in liver grafts were categorized since their effects on outcomes are not linear. Categorical data are expressed as numbers or percentages and the significance of differences between groups was analyzed using the chi-square test or Fisher's exact test. Kaplan-Meier curves were used to represent allograft survival. Diabetes-free survival rates were estimated by the Kaplan-Meier method using the logrank test. Patient death, graft loss, re-transplantation, and loss to follow-up were censored in the diabetes-free survival analyses. Univariate and multivariate analyses for predicting NODAT development were performed using a Cox proportional hazard model. All $\mathrm{P}$ values were two-tailed, and a $\mathrm{P}$ value at or below 0.05 was considered statistically significant. All statistical analyses were performed using SAS version 9.4 (SAS, Inc., Cary, NC, USA) and SPSS ver. 22.0 (SPSS, Inc., Chicago, IL, USA).

\section{Results}

\section{The incidence of NODAT}

NODAT occurred in 377 (19.7\%) of 1,919 liver recipients with a mean follow-up time of $13.1 \pm 10.6$ months. The incidence of NODAT was $19.6 \%$ and $20.8 \%$ at 6 and 12 months after LT, respectively (Figure 1). A total of $447(23.3 \%)$ and 1,472 (76.7\%) patients received DDLT and LDLT, respectively. The incidence of NODAT in 
A

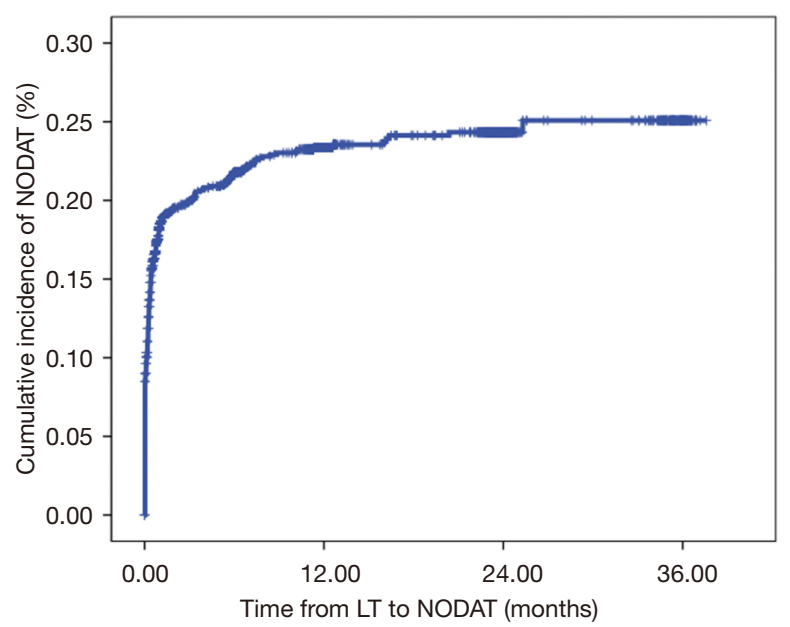

B

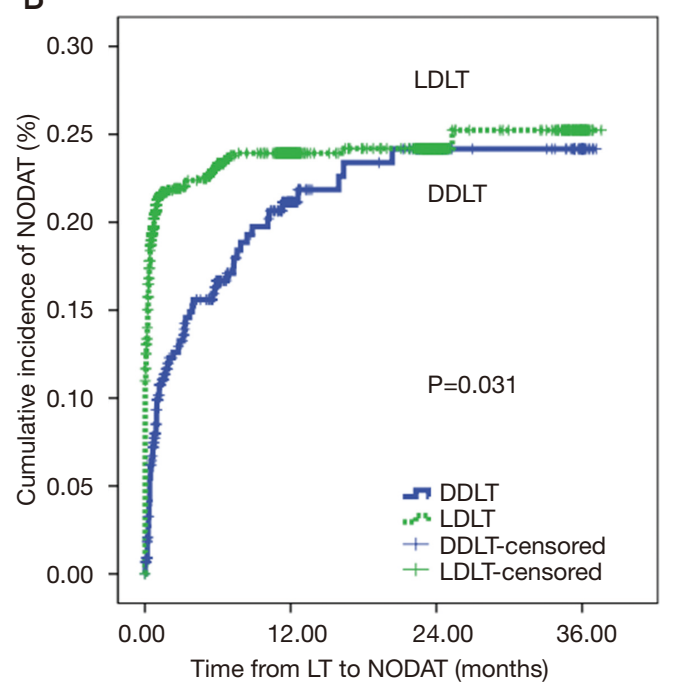

Figure 1 NODAT incidence. (A) New-onset diabetes after transplantation (NODAT) incidence in adult liver recipients and (B) NODAT incidence in DDLT and LDLT recipients.

the LDLT group was greater than in the DDLT group $(\mathrm{P}=0.031)$.

The recipient, donor, and immunosuppression variables according to the presence of NODAT are summarized in Table 1. The recipients who developed NODAT were older, had higher BMI, and included a greater proportion of living-related donors, open donor hepatectomy, and small size liver grafts (GRWR $\leq 0.8)$ compared with patients without NODAT. With regard to immunosuppression, the proportion of basiliximab induction, cyclosporine use, and steroid use in patients with NODAT was greater than in patients without NODAT, but antimetabolite use in the patients with NODAT was lower than in patients without NODAT (Table 1).

\section{Risk factors for NODAT}

Multivariate analyses showed that increased recipient age, high recipient BMI, implantation of left-side liver graft, and steroid use were predisposing factors for developing NODAT in adult LT patients, whereas basiliximab induction and antimetabolite use were significantly associated with a decreased risk of NODAT (Table 2). In DDLT patients, increased recipient age (HR, 1.028; 95\% CI, 1.005-1.052; $\mathrm{P}=0.020$ ) was only an independent factor for NODAT (Table S1). In LDLT patients, increased recipient age, high recipient BMI, Child-Pugh class, small size liver grafts (GRWR $\leq 0.8)$, and steroid use were predisposing factors for NODAT, but the presence of HCC, minimally invasive donor hepatectomy, basiliximab induction, and antimetabolite use were closely associated with protective effects against NODAT (Table 3).

\section{Graft survival}

We found no significant difference in terms of the graft survival rates between patients with NODAT and patients without NODAT (Figure 2). In fact, we found that the graft survival rates in patients with NODAT were similar to those in patients without NODAT after DDLT and LDLT.

\section{Discussion}

In this study using the KOTRY liver transplant database, NODAT was reported in $19.7 \%$ of recipients of an initial liver graft with a median follow-up time of 1 year. In fact, most of the NODAT cases in this study $(90 \%)$ reported within 6 months after liver transplant. The incidence of diabetes is $10.22 \%$ in middle-aged Koreans (20). Therefore, the incidence of NODAT is higher than that of diabetes in general population. A study based on the Organ Procurement and Transplant Network/United Network for Organ Sharing (OPTN/UNOS) liver transplant database showed that NODAT occurred in $26.4 \%$ of liver recipients with a median follow-up of about 2 years, and more than $80 \%$ of NODAT occurred within 1 year after LT. The onset 
Table 1 Comparison of transplant patients with and without NODAT

\begin{tabular}{|c|c|c|c|}
\hline Variables & No NODAT $(n=1,542)$ & NODAT $(n=377)$ & $P$ value \\
\hline Recipient age & $52.7 \pm 9.4$ & $54.8 \pm 8.1$ & $<0.001$ \\
\hline Recipient hypertension & $103(6.7)$ & $23(6.1)$ & 0.816 \\
\hline Recipient body mass index & $23.8 \pm 3.6$ & $24.6 \pm 3.8$ & $<0.001$ \\
\hline$<18.5$ & $69(4.5)$ & $20(5.3)$ & \\
\hline $18.5-25$ & $953(61.9)$ & $196(52.0)$ & \\
\hline $25-30$ & $433(28.1)$ & $129(34.2)$ & \\
\hline$>30$ & $85(5.5)$ & $32(8.5)$ & \\
\hline HBV & $892(57.8)$ & $214(56.8)$ & \\
\hline $\mathrm{HCV}$ & $107(6.9)$ & $30(8.0)$ & \\
\hline Alcoholic & $351(22.8)$ & $89(23.6)$ & \\
\hline Cryptogenic & $66(4.3)$ & $21(5.6)$ & \\
\hline Others & $126(8.2)$ & $23(6.1)$ & \\
\hline Hepatocellular carcinoma & $772(50.1)$ & $175(46.4)$ & 0.207 \\
\hline Child-Pugh class & & & 0.883 \\
\hline$A$ & $477(30.9)$ & $103(27.3)$ & \\
\hline $15-34$ & $592(38.4)$ & $158(41.9)$ & \\
\hline$\geq 35$ & $175(11.3)$ & $30(8.0)$ & \\
\hline Urgent status in KONOS & & & 0.151 \\
\hline 1 & $35(2.3)$ & $9(2.4)$ & \\
\hline 2 & $123(8.0)$ & $17(4.5)$ & \\
\hline 3 & $91(5.9)$ & $26(6.9)$ & \\
\hline 4 & $253(16.4)$ & $58(15.4)$ & \\
\hline 5 & $1,040(67.4)$ & $267(70.8)$ & \\
\hline ABO-incompatible & $236(15.3)$ & $68(18.0)$ & 0.208 \\
\hline
\end{tabular}

Table 1 (continued) 
Table 1 (continued)

\begin{tabular}{|c|c|c|c|}
\hline Variables & No NODAT $(\mathrm{n}=1,542)$ & NODAT $(n=377)$ & $P$ value \\
\hline Whole & $355(23.0)$ & $71(18.8)$ & \\
\hline Left-side graft & $46(3.0)$ & $21(5.6)$ & \\
\hline Right-side graft & $1,141(74.0)$ & $285(75.6)$ & \\
\hline Macrosteatosis in donor & & & 0.464 \\
\hline$<10 \%$ & $1,197(77.6)$ & $313(83.0)$ & \\
\hline $10-30 \%$ & $186(12.1)$ & $46(12.2)$ & \\
\hline$>30 \%$ & $32(2.1)$ & $5(1.3)$ & \\
\hline Living donor liver transplantation $(n=1,472)$ & 1,170 & 302 & \\
\hline Relationship in LDLT & & & $<0.001$ \\
\hline Living-related donor & $901(77.0)$ & $275(91.1)$ & \\
\hline Living-unrelated donor & $269(23.0)$ & $27(8.9)$ & \\
\hline Living donor operation (minimally invasive surgery) & $184(15.7)$ & $28(9.3)$ & 0.004 \\
\hline GRWR & $1.17 \pm 0.31$ & $1.13 \pm 0.31$ & 0.008 \\
\hline GRWR $>0.8$ in LDLT & $1,062(90.8)$ & $258(85.4)$ & 0.003 \\
\hline Use of mTOR inhibitors at 6 months post-transplant & $170(11.0)$ & $35(9.3)$ & 0.353 \\
\hline Donor gender (male) & $991(64.3)$ & $233(61.8)$ & 0.371 \\
\hline Donor age (years) & $35.3 \pm 14.3$ & $34.0 \pm 13.0$ & 0.228 \\
\hline Hypertension in donor & $103(6.7)$ & $23(6.1)$ & 0.644 \\
\hline Diabetes in donor & $49(3.2)$ & $10(2.7)$ & 0.475 \\
\hline Donor body mass index & $23.2 \pm 3.2$ & $23.3 \pm 3.0$ & 0.484 \\
\hline Donor body mass index & & & 0.095 \\
\hline$<18.5$ & $73(4.7)$ & $15(4.0)$ & \\
\hline $18.5-25$ & $1,063(68.9)$ & 276 (73.2) & \\
\hline $25-30$ & 358 (23.2) & $78(20.7)$ & \\
\hline$>30$ & $47(3.0)$ & $8(2.1)$ & \\
\hline Unknown & $1(0.1)$ & - & \\
\hline
\end{tabular}

Data are shown as mean \pm standard deviation or number (percentage). 
Table 2 Risk factors for NODAT in adult liver transplant patients $(\mathrm{n}=1,919)$

\begin{tabular}{|c|c|c|c|c|c|c|}
\hline Variables & \multicolumn{3}{|c|}{ Univariate } & \multicolumn{3}{|c|}{ Multivariate } \\
\hline Recipient gender (male) & 1.17 & $0.931-1.469$ & 0.178 & & & \\
\hline Recipient age & 1.024 & $1.012-1.036$ & $<0.001$ & 1.022 & $1.010-1.034$ & $<0.001$ \\
\hline Hypertension in recipients & 1.346 & $1.035-1.750$ & 0.027 & & & \\
\hline$<18.5$ & 1 & 1 & & 1 & 1 & \\
\hline $18.5-24$ & 0.728 & $0.460-1.153$ & & 0.729 & $0.458-1.159$ & \\
\hline $25-29$ & 1.029 & $0.642-1.648$ & & 1.028 & $0.638-1.656$ & \\
\hline$\geq 30$ & 1.245 & $0.712-2.177$ & & 1.242 & $0.706-2.185$ & \\
\hline Cryptogenic & 1.259 & $0.782-2.025$ & & & & \\
\hline Hepatitis B virus & 0.946 & $0.739-1.212$ & & & & \\
\hline Hepatitis C virus & 1.057 & $0.699-1.599$ & & & & \\
\hline Others & 0.733 & $0.463-1.159$ & & & & \\
\hline Hepatocellular carcinoma & 0.878 & $0.717-1.075$ & 0.208 & & & \\
\hline Disease progression & & & 0.092 & & & \\
\hline Cirrhosis & 1 & 1 & & & & \\
\hline Acute & 0.938 & $0.584-1.507$ & & & & \\
\hline MELD score & & & 0.175 & & & \\
\hline$<15$ & 1 & 1 & & & & \\
\hline $15-34$ & 1.07 & $0.866-1.322$ & & & & \\
\hline$\geq 35$ & 0.738 & $0.502-1.085$ & & & & \\
\hline Urgent status in KONOS & & & 0.363 & & & \\
\hline 1 & 1 & 1 & & & & \\
\hline 1 (retransplantation) & 2.351 & $0.295-18.739$ & & & & \\
\hline 2 & 0.64 & $0.276-1.483$ & & & & \\
\hline 3 & 1.139 & $0.516-2.516$ & & & & \\
\hline 4 & 0.972 & $0.464-2.035$ & & & & \\
\hline 5 & 1.075 & $0.532-2.171$ & & & & \\
\hline
\end{tabular}

Table 2 (continued) 
Table 2 (continued)

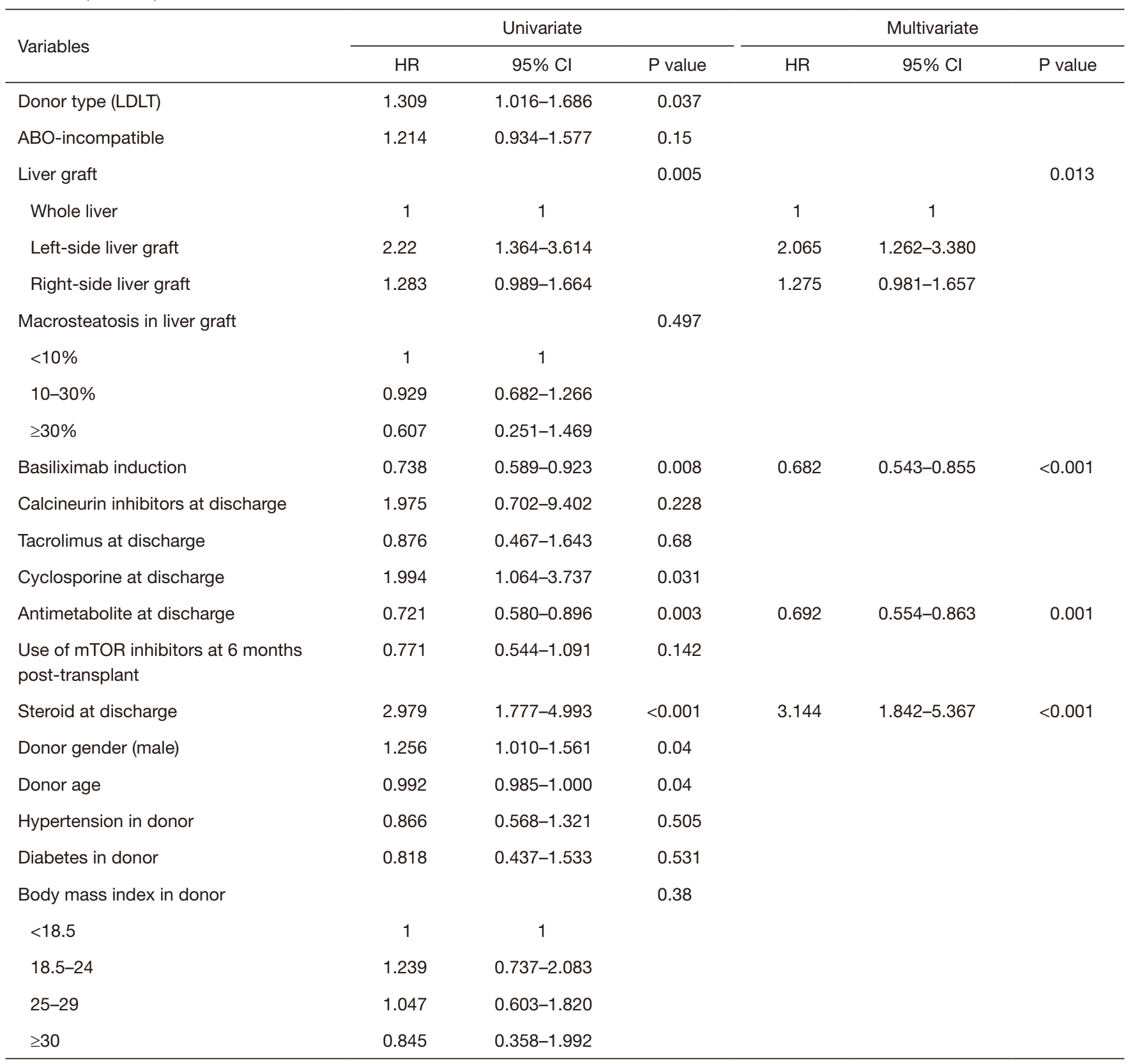

of diabetes within the first 6 months of LT has been found to be associated with high doses of corticosteroid, and with immune suppression due to other medications and physical inactivity $(1,4,5,7,10,12,21,22)$.

The reported incidence of NODAT after LT ranges from $7 \%$ to $30 \%$; the differences between study results may have been due to differences in diagnostic criteria, statistical methods, use of immunosuppressive agents, the length of follow-up and study populations $(1,4,9,10)$. The timing of diagnostic screening for NODAT is also important. Almost all patients will have post-operative hyperglycemia due to the stress of surgery and administration of high-dose steroids. In addition, post-transplant patients may suffer from surgical complications, infections, and other comorbid conditions in the first year, leading to hospitalizations and "stress" itself during that time $(23,24)$. 
Table 3 Risk factors for NODAT in adult living donor liver transplant patients ( $\mathrm{n}=1,473)$

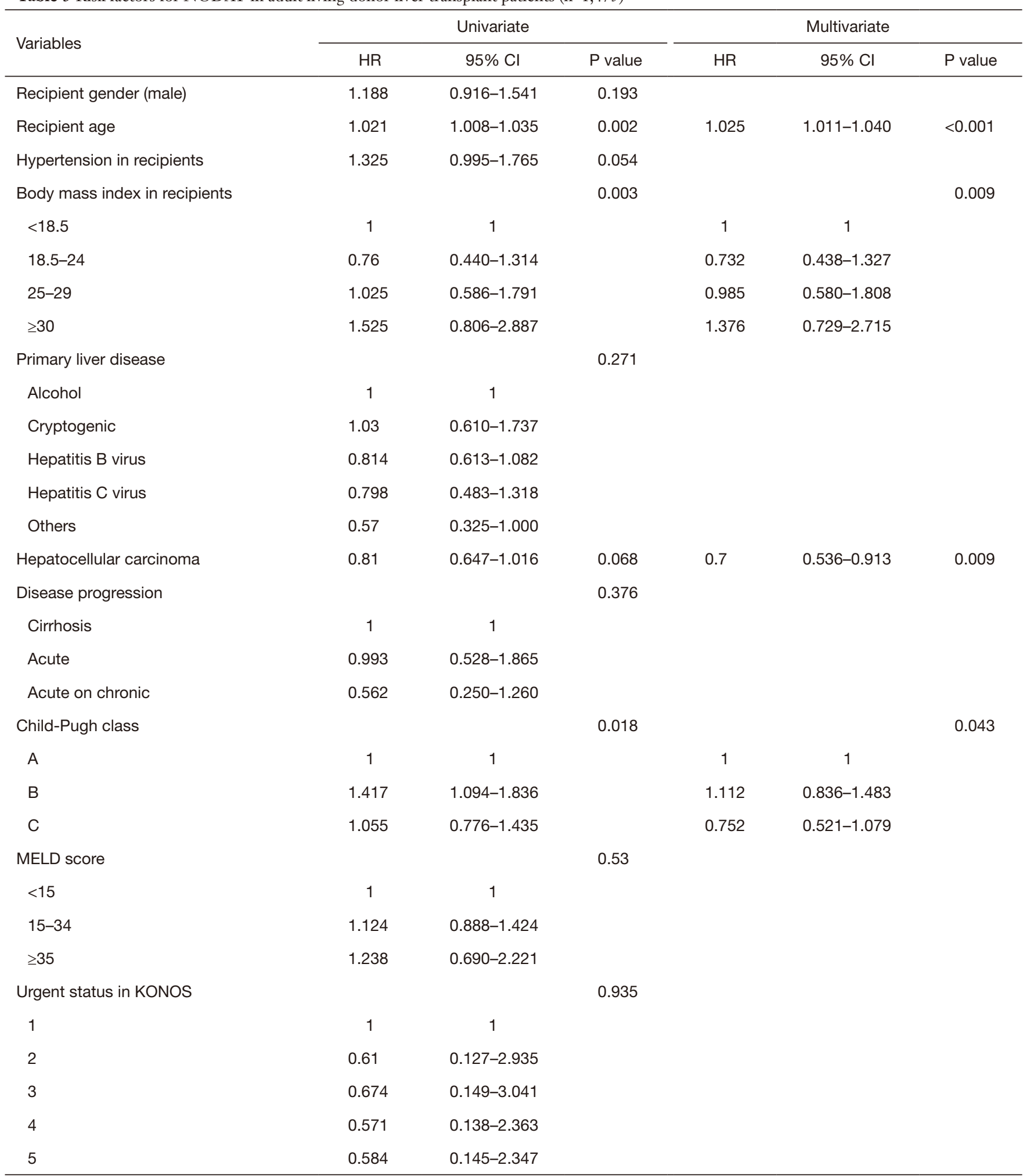

Table 3 (continued) 
Table 3 (continued)

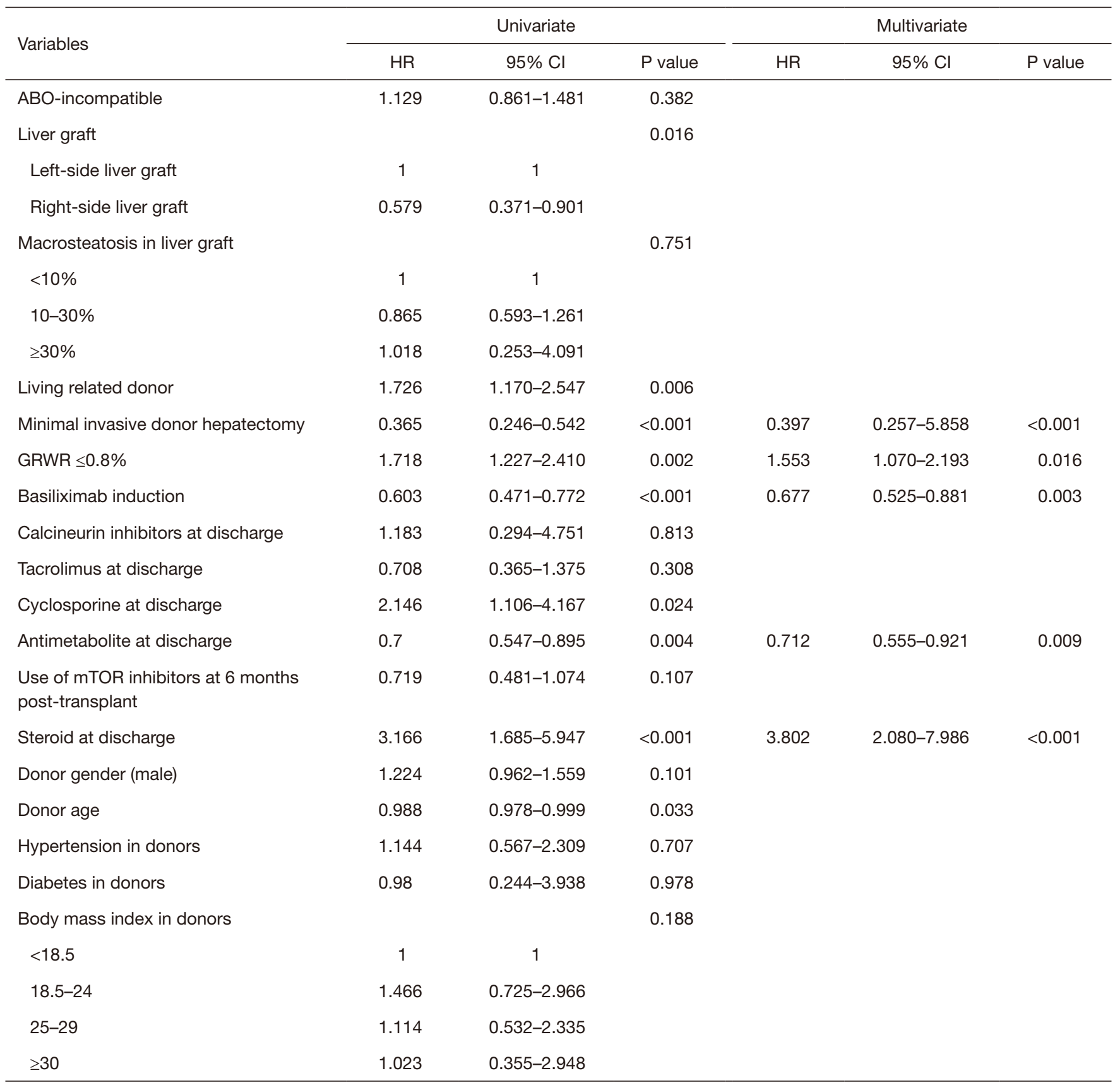

LT populations in Korea and Western countries differ in several aspects, such as race, diet, genetic background and etiology of liver diseases. HCV infection, obesity and alcoholic cirrhosis are the three major risk factors of NODAT in Western countries, but not in Korea. It is unclear if the incidence of NODAT in Korean transplant recipients is similar to that in Western countries. It is also unclear whether NODAT is related to the primary liver disease, donor liver, surgical procedures and/or the use of immunosuppressive treatments.

In our study, recipient risk factors for NODAT identified in adult post-transplant patients by multivariate analyses were increased age, high recipient BMI, steroid use, and left-side liver graft, while basiliximab induction 

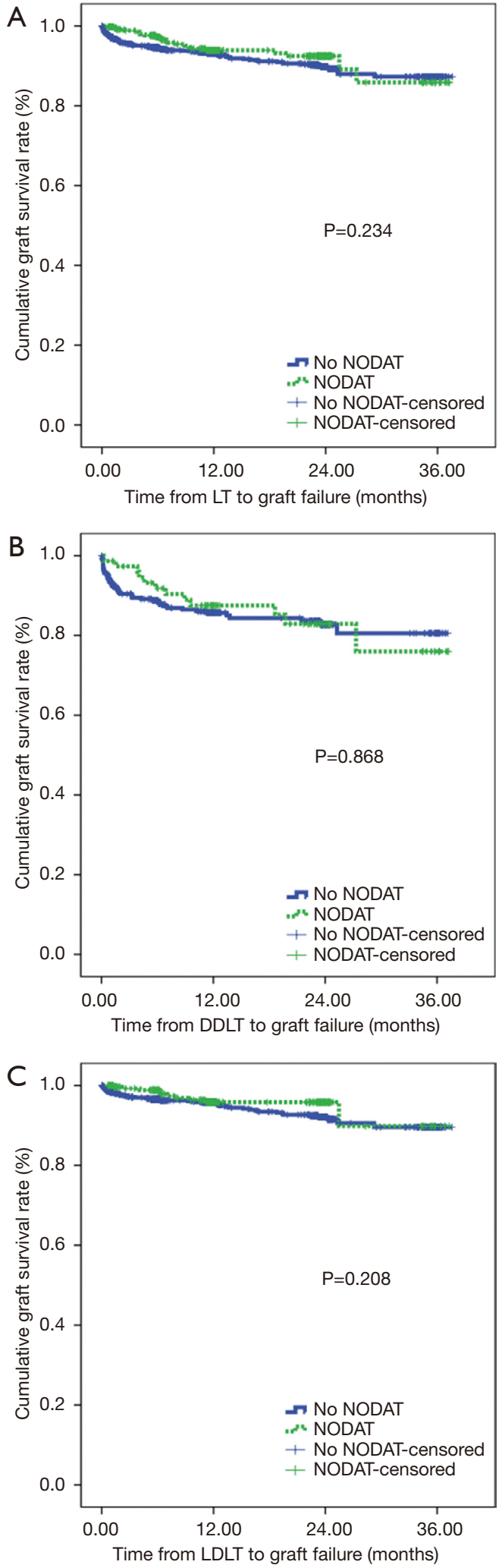

Figure 2 Graft survival: (A) all adult LT patients, (B) DDLT patients, and (C) LDLT patients. and antimetabolite use had a protective effect on the development of NODAT. In adult LDLT patients, risk factors for NODAT were increased recipient age, patients without HCC, high recipient BMI, advanced liver cirrhosis, steroid use, open donor hepatectomy, and small size liver grafts (GRWR $\leq 0.8$ ), while basiliximab induction and antimetabolite use had a protective effect.

Increased age is an established risk factor for NODAT in liver transplant recipients. A previous study reported older age as an independent predictor for NODAT in a cohort of 555 liver transplant recipients (25). A more recent study using OPTN/SRTR data also reported increased recipient age ( $\geq 50$ years) as a risk factor for NODAT in a cohort of 15,463 liver transplant recipients (12). In this study, increased recipient age was an independent risk factor for NODAT in both adult LDLT and DDLT recipients.

Obesity has been shown to be an independent risk factor for NODAT in LT. A previous multicenter study reported that a BMI greater than $25 \mathrm{~kg} / \mathrm{m}^{2}$ was associated with an increased risk of NODAT (26). OPTN/SRTR data revealed that overweight/obesity (BMI $\geq 25 \mathrm{~kg} / \mathrm{m}^{2}$ ) was associated with an $18.6 \%$ increased risk for NODAT in LT recipients after adjustment for other factors (12). Our study showed that obesity (recipient BMI $\geq 30 \mathrm{~kg} / \mathrm{m}^{2}$ ) was an independent factor in adult LT and LDLT patients. However, the predictive effect of the recipient BMI should be interpreted with caution, due to severe ascites contributing to the high BMI values in some patients. Additionally, present study showed that non-HCC patients were related with NODAT. The median MELD score in HCC patients is lower than in the non-HCC patients (10 vs. 20, $\mathrm{P}<0.001)$. Additionally, the proportion of Child-Pugh class $\mathrm{C}$ in the HCC patients was lower than in the non-HCC patients $(16.1 \%$ vs. $60.1 \%$, $\mathrm{P}<0.001)$. Physical inactivity or poor performance might contribute NODAT development in terms of elderly recipient, obesity, and advanced liver cirrhosis.

Specific immunosuppressive regimens may influence the development of NODAT after solid organ transplantation. In liver recipients, maintenance immunosuppression with tacrolimus and steroid has been associated with an increased risk of NODAT (22-24,27). In this study, both tacrolimus and steroid use at discharge were associated with an increased risk of NODAT in LT recipients in univariate and multivariate analyses, whereas basiliximab induction therapy and use of antimetabolite at discharge were associated with a decreased risk. However, we found that the use of mammalian target of rapamycin inhibitors at 6 months was not associated with the risk of NODAT. 
In present study, $76.9 \%$ of liver recipients had induction therapy. The incidence of NODAT was significantly lower in recipients who received induction therapy, compared with those who $\operatorname{did} \operatorname{not}(\mathrm{P}=0.008)$. In the multivariate analysis, induction therapy decreased the risk of NODAT in adult LT and LDLT recipients. Basiliximab induction reduced the risk of NODAT onset in adult LT and LDLT, with odd ratios of 0.682 and 0.677 , respectively. We thought that basiliximab induction and antimetabolites allow to decrease tacrolimus exposure, thus resulting in reduced risk of NODAT. if needed. In meta-analysis studies, induction therapy with steroid-free immunosuppression has been shown to decrease the incidence of NODAT in LT recipients $(23,24)$.

Corticosteroids have a well-recognized diabetogenic effect; the main mechanism underlying this effect is insulin resistance, which causes increased hepatic gluconeogenesis (22-24,27). Meta-analyses of LT study data found that withdrawal of glucocorticoids after LT may reduce the risk of NODAT, and no unfavorable effects were observed after steroid withdrawal over short-term follow up $(23,24)$. Suggested mechanisms for the hyperglycemia related to NODAT include increased insulin resistance, increased hepatic gluconeogenesis, and decreased insulin secretion (28). The risk of NODAT increases proportionally to both the dose and duration of corticosteroid therapy (22-24).

Previous studies have reported that antiproliferative agents and mTOR inhibitors do not cause hyperglycemia. However, our study revealed that use of antimetabolite reduced the incidence of NODAT, but mTOR inhibitors did not affect NODAT occurrence. The known side effects of calcineurin inhibitors include diabetes, possibly as a result of impaired insulin secretion and sensitivity, inhibition of insulin gene transcription and/or direct damage to pancreatic islet cells (29). There is evidence indicating the incidence of NODAT is greater in LT patients receiving tacrolimus compared with those treated with cyclosporine (11), but the reason for this difference is unclear (30). A recent study reported that a minimal tacrolimus regimen can decrease the risk of long-term NODAT after LT (21). Univariate analyses of our data found that cyclosporine usage predicted NODAT, but multivariate analyses found cyclosporine treatment did not predict NODAT in adult LT and LDLT patients. Our study did not demonstrate tacrolimus use or cyclosporine use were not risk factor for NODAT because many patients (97.3\%) in our study population accounted for the tacrolimus. In addition, the combination of low dose calcineurin inhibitors and antimetabolite is commonly used for maintenance therapy in Korea.

The associations between small size liver graft or minimally invasive donor hepatectomy in living donor hepatectomy and NODAT have rarely been examined in previous studies. Logistic regression analyses in the present study found that small size liver graft (GRWR $\leq 0.8$ ) or minimally invasive donor hepatectomy, including laparoscopic donor hepatectomy or robotic donor hepatectomy, in LDLT were independent risk factors for NODAT. Three to five centers performed the minimal invasive donor hepatectomy according to their indications. Laparoscopic donor hepatectomy in our center performed nearly all cases. The mechanism underlying the influence of these factors on the occurrence of NODAT in the LT recipients from living donor hepatectomy is unclear, but we speculate that hepatic inflammation may be involved. We cannot explain clearly the protective effect of minimal invasive donor hepatectomy in our study. More researches should be needed to define the relevance of small size liver graft or minimally invasive donor hepatectomy to developing NODAT.

Liver surgery induces acute hepatic inflammation, which is characterized by the production and release of various chemical mediators, including cytokines (31). An increase in lipid peroxidation was found to be important for normal proliferative processes to occur in the remnant liver after partial hepatectomy (31). The pathophysiology of hepatic ischemic-reperfusion injury is not only related to the direct cell impairment caused by ischemic insult, but also results from the restoration of blood flow, which triggers the proinflammatory environment (32). Therefore, ischemicreperfusion injury is associated with inflammation and oxidation processes. Reactive oxygen species and oxidative stress in hepatic ischemic/reperfusion injury ultimately result in the production of lipid peroxidation (33). LT using small size liver grafts $(\mathrm{GRWR} \leq 0.8)$ leads to rapid post-transplant liver regeneration, while obtaining liver grafts through open donor hepatectomy requires a large incision. Both small size liver grafts and large incision may induce greater production of reactive oxygen species and oxidative stress in the donors or recipients compared to LT using liver grafts procured by minimally invasive donor hepatectomy from living liver donors or using liver grafts with sufficient volumes. This topic requires further investigation.

The association of chronic liver disease with impaired glucose metabolism is well known. In cirrhotic patients, the 
prevalence of impaired glucose tolerance is estimated to be approximately $60 \%$ to $80 \%$ (34). Analysis of OPTN/SRTR data indicated that pre-transplant cirrhosis (alcoholic or non-alcoholic) was an independent risk factor for NODAT in liver transplant recipients (12), but our data showed that pre-transplant cirrhosis or urgent status for liver transplant candidates could not predict NODAT in Korean LT recipients.

The findings from published studies regarding the effect of NODAT on graft failure or patient death after LT are inconsistent. Previous studies reported significantly lower survival rates of both recipients and grafts in the patients who developed NODAT compared to non-NODAT patients $(2,11)$. However, other studies reported that the 1 and 2-year survival rates did not differ significantly between the two patient groups $(7,12,35)$. Our study also found NODAT did not have an impact on patient survival.

NODAT is a common and serious complication after LT in Western countries and China $(10,12)$, however, it does not seem to influence graft survival in the adult Korean LT recipients in our study. One should note, however, that the follow-up duration in our study was relatively short. Timely intervention for treatment of hyperglycemia may prevent poor outcomes in patients who develop NODAT. In Korea, the government, academic expert groups, national insurance program, and hospitals are very active in the diagnosis, treatment, and management of diabetes, which may serve to reduce diabetes-related complications (36).

Our large prospective cohort study has several limitations that warrant consideration. First, the KOTRY database does not include actual medical examination data, such as physical examination findings and laboratory results, or intraoperative data, such as operative time, hemodynamics, or medications used during surgery that may be closely linked to the development of NODAT after LT. Other large transplant-related datasets may contain data not available in the KOTRY-based datasets. Second, the KOTRY database is heterogeneous and subject to flaws inherent in the nature of all registry databases such as reporting bias or error. NODAT is defined based on follow-up reporting to the KOTRY database. The actual incidence of NODAT is difficult to determine due to different definitions of NODAT being used by the 15 medical centers reporting transplant data to the KOTRY. The date of NODAT events reported to the KOTRY may be inconsistent with the actual date of NODAT onset. In addition, immunosuppression protocols and the management of NODAT in participating institutions are heterogeneous. Third, the follow-up period in our study was relatively short, with a median follow-up duration of about one year, therefore the effect of NODAT on end-stage renal disease, long-term graft and patient survival could not be assessed. Additionally, KOTRY database does not have information regarding diabetes therapy such as insulin or oral drugs, surveillance, or screening of vascular complications. Further studies using a longer follow-up time are needed to assess the longterm effects of NODAT on cardiovascular events, graft and patient outcomes in LT.

Nonetheless, the present study is the first to assess the incidence of NODAT in Korean LT patients included in the KOTRY database, and the results may be informative for future transplant patient management. In addition, our study is one of the largest prospective registry studies of NODAT following adult LT. These data are also meaningful in reflecting racial and social differences between western and Asian countries. Present study contributed the change of our center's policy which included minimal invasive donor hepatectomy in nearly all LDLT cases and immunosuppressive protocols after LT.

In conclusion, the incidence of NODAT is about $20 \%$ within the first year after adult LT in Korean transplant recipients. Advanced recipient age, high $\mathrm{BMI}$ in recipient, and implantation of a left-side liver graft increased the risk of NODAT in adult LT patients, while basiliximab induction and use of antimetabolite decreased the risk of NODAT in these patients. Along with the same risk factors for NODAT in adult LT patients, small size liver grafts or open donor hepatectomy were also found to increase the risk of NODAT in LDLT recipients. The present study showed that NODAT did not affect graft survival over the relatively short follow-up period in patients who were not non-diabetic before transplantation.

The findings indicate greater attention should be paid to monitoring and managing impaired glucose regulation after transplantation to prevent renal dysfunction, which should improve the long-tern survival and quality of life of LT recipients. Prospective studies are needed to identify whether modifiable risk factors are present before and/or after LT to reduce the incidence of NODAT.

\section{Acknowledgments}

We would like to thank the MRCC for data extraction and analysis. 
Funding: This research was supported by a fund by Research of Korea Centers for Disease Control and Prevention (2014-ER6301-00, 2014-ER6301-01, 2014-ER6301-02, 2017-ER6301-00, 2017-ER6301-01).

\section{Footnote}

Reporting Checklist: The authors have completed the STROBE reporting checklist. Available at http://dx.doi. org/10.21037/hbsn.2019.10.29

Data Sharing Statement: Available at http://dx.doi. org/10.21037/hbsn.2019.10.29

Conflicts of Interest: All authors have completed the ICMJE uniform disclosure form (available at http://dx.doi. org/10.21037/hbsn.2019.10.29). The authors have no conflicts of interest to declare.

Ethical Statement: The authors are accountable for all aspects of the work in ensuring that questions related to the accuracy or integrity of any part of the work are appropriately investigated and resolved. This study was approved by the KOTRY, which is the only authorized national LT registry in South Korea. The study was initiated after obtaining approval from the ethics committee for each participating center, according to the Regulations on Human Organ Transplant and national legal requirements. The procedures were in accordance with the Helsinki declaration. All patients provided informed consent prior to participation in the study.

Open Access Statement: This is an Open Access article distributed in accordance with the Creative Commons Attribution-NonCommercial-NoDerivs 4.0 International License (CC BY-NC-ND 4.0), which permits the noncommercial replication and distribution of the article with the strict proviso that no changes or edits are made and the original work is properly cited (including links to both the formal publication through the relevant DOI and the license). See: https://creativecommons.org/licenses/by-ncnd/4.0/.

\section{References}

1. Wallia A, Illuri V, Molitch ME. Diabetes Care After Transplant: Definitions, Risk Factors, and Clinical Management. Med Clin North Am 2016;100:535-50.
2. Moon JI, Barbeito R, Faradji RN, et al. Negative impact of new-onset diabetes mellitus on patient and graft survival after liver transplantation: Long-term follow up. Transplantation 2006;82:1625-8.

3. Baid S, Cosimi AB, Farrell ML, et al. Posttransplant diabetes mellitus in liver transplant recipients: risk factors, temporal relationship with hepatitis $\mathrm{C}$ virus allograft hepatitis, and impact on mortality. Transplantation 2001;72:1066-72.

4. Lv C, Zhang Y, Chen X, et al. New-onset diabetes after liver transplantation and its impact on complications and patient survival. J Diabetes 2015;7:881-90.

5. Li DW, Lu TF, Hua XW, et al. Risk factors for new onset diabetes mellitus after liver transplantation: A metaanalysis. World J Gastroenterol 2015;21:6329-40.

6. Sarno G, Mehta RJ, Guardado-Mendoza R, et al. Newonset diabetes mellitus: predictive factors and impact on the outcome of patients undergoing liver transplantation. Curr Diabetes Rev 2013;9:78-85.

7. Yagi S, Kaido T, Iida T, et al. New-onset diabetes mellitus after living-donor liver transplantation: association with graft synthetic function. Surg Today 2017;47:733-42.

8. Gebhardt S, Jara M, Malinowski M, et al. Risk factors of metabolic disorders after liver transplantation: an analysis of data from fasted patients. Transplantation 2015;99:1243-9.

9. Parekh J, Corley DA, Feng S. Diabetes, hypertension and hyperlipidemia: prevalence over time and impact on longterm survival after liver transplantation. Am J Transplant 2012;12:2181-7.

10. Ling Q, Xu X, Xie H, et al. New-onset diabetes after liver transplantation: a national report from China Liver Transplant Registry. Liver Int 2016;36:705-12.

11. Xu X, Ling Q, He ZL, et al. Post-transplant diabetes mellitus in liver transplantation: Hangzhou experience. Hepatobiliary Pancreat Dis Int 2008;7:465-70.

12. Kuo HT, Sampaio MS, Ye X, et al. Risk factors for newonset diabetes mellitus in adult liver transplant recipients, an analysis of the Organ Procurement and Transplant Network/United Network for Organ Sharing database. Transplantation 2010;89:1134-40.

13. Chapman J. Transplantation practice has been particularly suited to national, regional, specialist and global registries. Transplant Rev (Orlando) 2013;27:37.

14. Massie AB, Kucirka LM, Segev DL. Big data in organ transplantation: registries and administrative claims. Am J Transplant 2014;14:1723-30.

15. Lee JG, Lee KW, Kwon CHD, et al. Donor safety 
in living donor liver transplantation: The Korean organ transplantation registry study. Liver Transpl 2017;23:999-1006.

16. Yang J, Jeong JC, Lee J, et al. Design and Methods of the Korean Organ Transplantation Registry. Transplant Direct 2017;3:e191.

17. American Diabetes Association. Diagnosis and classification of diabetes mellitus. Diabetes Care 2012;35 Suppl 1:S64-71.

18. Levey AS, Inker LA, Coresh J. GFR estimation: from physiology to public health. Am J Kidney Dis 2014;63:820-34.

19. Min SI, Ahn C, Han DJ, et al. To achieve national selfsufficiency: recent progresses in deceased donation in Korea. Transplantation 2015;99:765-70.

20. Boo S, Yoon YJ, Oh H. Evaluating the prevalence, awareness, and control of hypertension, diabetes, and dyslipidemia in Korea using the NHIS-NSC database: A cross-sectional analysis. Medicine (Baltimore) 2018;97:e13713.

21. Song JL, Gao W, Zhong Y, et al. Minimizing tacrolimus decreases the risk of new-onset diabetes mellitus after liver transplantation. World J Gastroenterol 2016;22:2133-41.

22. Kim YK, Lee KW, Kim SH, et al. Early steroid withdrawal regimen prevents new-onset diabetes mellitus in old-age recipients after living donor liver transplantation. World J Surg 2012;36:2443-8.

23. Sgourakis G, Radtke A, Fouzas I, et al. Corticosteroidfree immunosuppression in liver transplantation: a metaanalysis and meta-regression of outcomes. Transpl Int 2009;22:892-905.

24. Segev DL, Sozio SM, Shin EJ, et al. Steroid avoidance in liver transplantation: meta-analysis and meta-regression of randomized trials. Liver Transpl 2008;14:512-25.

25. Khalili M, Lim JW, Bass N, et al. New onset diabetes mellitus after liver transplantation: the critical role of hepatitis C infection. Liver Transpl 2004;10:349-55.

26. Saliba F, Lakehal M, Pageaux GP, et al. Risk factors for new-onset diabetes mellitus following liver transplantation and impact of hepatitis $\mathrm{C}$ infection : an observational multicenter study. Liver Transpl 2007;13:136-44.

27. Oufroukhi L, Kamar N, Muscari F, et al. Predictive factors for posttransplant diabetes mellitus within one-year of liver transplantation. Transplantation 2008;85:1436-42.
28. van Raalte DH, Ouwens DM, Diamant M. Novel insights into glucocorticoid-mediated diabetogenic effects: towards expansion of therapeutic options? Eur J Clin Invest 2009;39:81-93.

29. Markell M. New-onset diabetes mellitus in transplant patients: pathogenesis, complications, and management. Am J Kidney Dis 2004;43:953-65.

30. Heisel O, Heisel R, Balshaw R, et al. New onset diabetes mellitus in patients receiving calcineurin inhibitors: $\mathrm{a}$ systematic review and meta-analysis. Am J Transplant 2004;4:583-95.

31. Mendes-Braz M, Martins JO. Diabetes Mellitus and Liver Surgery: The Effect of Diabetes on Oxidative Stress and Inflammation. Mediators Inflamm 2018;2018:2456579.

32. Donadon M, Molinari AF, Corazzi F, et al. Pharmacological Modulation of Ischemic-Reperfusion Injury during Pringle Maneuver in Hepatic Surgery. A Prospective Randomized Pilot Study. World J Surg 2016;40:2202-12.

33. Rehman K, Akash MSH. Mechanism of Generation of Oxidative Stress and Pathophysiology of Type 2 Diabetes Mellitus: How Are They Interlinked? J Cell Biochem 2017;118:3577-85.

34. Konrad T, Steinmuller T, Vicini P, et al. Evidence for impaired glucose effectiveness in cirrhotic patients after liver transplantation. Metabolism 2000;49:367-72.

35. John PR, Thuluvath PJ. Outcome of liver transplantation in patients with diabetes mellitus: a case-control study. Hepatology 2001;34:889-95.

36. Ko SH, Han K, Lee YH, et al. Past and Current Status of Adult Type 2 Diabetes Mellitus Management in Korea: A National Health Insurance Service Database Analysis. Diabetes Metab J 2018;42:93-100.

Cite this article as: Kim JM, Hwang S, Lee KW, Lee JG, Ryu JH, Kim BW, Choi DL, You YK, Kim DS, Nah YW, Kang KJ, Cho JY, Hong G, Choi IS, Yu HC, Choi D, Kim MS The Korean Organ Transplantation Registry Study Group. New-onset diabetes after adult liver transplantation in the Korean Organ Transplantation Registry (KOTRY) study. HepatoBiliary Surg Nutr 2020;9(4):425-439. doi: 10.21037/ hbsn.2019.10.29 
Table S1 The risk factors for NODAT in adult deceased donor liver transplant patients ( $\mathrm{n}=446$ )

\begin{tabular}{|c|c|c|c|c|c|c|}
\hline \multirow{2}{*}{ Factors } & \multicolumn{3}{|c|}{ Univariate } & \multicolumn{3}{|c|}{ Multivariate } \\
\hline & $\mathrm{HR}$ & $95 \% \mathrm{Cl}$ & $P$ value & $\mathrm{HR}$ & $95 \% \mathrm{Cl}$ & $P$ value \\
\hline Recipient gender (male) & 1.066 & $0.660-1.723$ & 0.794 & & & \\
\hline Recipient age & 1.028 & $1.004-1.051$ & 0.02 & 1.028 & $1.005-1.052$ & 0.020 \\
\hline Hypertension in recipient & 1.278 & $0.657-2.486$ & 0.471 & & & \\
\hline Body mass index in recipient & & & 0.111 & & & \\
\hline$<18.5$ & 1 & 1 & & & & \\
\hline $18.5-24$ & 0.573 & $0.242-1.354$ & & & & \\
\hline $25-29$ & 0.97 & $0.399-2.359$ & & & & \\
\hline$\geq 30$ & 0.405 & $0.101-1.622$ & & & & \\
\hline Etiology & & & 0.484 & & & \\
\hline Alcohol & 1 & 1 & & & & \\
\hline Cryptogenic & 1.787 & $0.539-5.921$ & & & & \\
\hline Hepatitis B virus & 1.07 & $0.627-1.828$ & & & & \\
\hline Hepatitis C virus & 1.838 & $0.882-3.828$ & & & & \\
\hline Others & 1.254 & $0.565-2.780$ & & & & \\
\hline Hepatocellular carcinoma & 0.897 & $0.537-1.498$ & 0.677 & & & \\
\hline Disease progression & & & 0.323 & & & \\
\hline Cirrhosis & 1 & 1 & & & & \\
\hline Acute & 1.033 & $0.496-2.155$ & & & & \\
\hline Acute on chronic & 0.342 & $0.084-1.398$ & & & & \\
\hline Child-Pugh class & & & 0.59 & & & \\
\hline A & 1 & 1 & & & & \\
\hline B & 1.028 & $0.218-4.841$ & & & & \\
\hline C & 1.449 & $0.354-5.925$ & & & & \\
\hline MELD score & & & 0.386 & & & \\
\hline$<15$ & 1 & 1 & & & & \\
\hline $15-34$ & 1.054 & $0.546-2.036$ & & & & \\
\hline$\geq 35$ & 0.719 & $0.338-1.527$ & & & & \\
\hline Urgent status in KONOS & & & 0.505 & & & \\
\hline 1 & 1 & 1 & & & & \\
\hline 1 (Retransplantation) & 2.44 & $0.294-20.277$ & & & & \\
\hline 2 & 0.587 & $0.213-1.615$ & & & & \\
\hline 3 & 1.207 & $0.468-3.112$ & & & & \\
\hline 4 & 0.847 & $0.336-2.136$ & & & & \\
\hline 5 & 0.98 & $0.401-2.398$ & & & & \\
\hline Liver graft & & & 0.582 & & & \\
\hline Whole liver & 1 & 1 & & & & \\
\hline Left-side liver graft & 2.38 & $0.019-16.396$ & & & & \\
\hline Right-side liver graft & 1.597 & $0.526-3.700$ & & & & \\
\hline Macrosteatosis in liver graft & & & 0.49 & & & \\
\hline$<10 \%$ & 1 & 1 & & & & \\
\hline $10-30 \%$ & 1.191 & $0.673-2.108$ & & & & \\
\hline$\geq 30 \%$ & 0.568 & $0.177-1.828$ & & & & \\
\hline Basiliximab induction & 1.47 & $0.856-2.523$ & 0.163 & & & \\
\hline Calcineurin inhibitors at discharge & 2.836 & $0.410-358.067$ & 0.377 & & & \\
\hline Tacrolimus at discharge & 1.627 & $0.226-11.717$ & 0.629 & & & \\
\hline Cyclosporine at discharge & 1.127 & $0.157-8.107$ & 0.906 & & & \\
\hline Antimetabolite at discharge & 0.715 & $0.446-1.146$ & 0.163 & & & \\
\hline $\begin{array}{l}\text { Use of mTOR inhibitors at } 6 \text { months post- } \\
\text { transplant }\end{array}$ & 1.01 & $0.503-2.029$ & 0.977 & & & \\
\hline Steroid at discharge & 2.162 & $0.872-5.357$ & 0.096 & & & \\
\hline Donor gender (male) & 1.447 & $0.874-2.396$ & 0.151 & & & \\
\hline Donor age & 1.008 & $0.993-1.023$ & 0.31 & & & \\
\hline Hypertension in donor & 0.914 & $0.519-1.609$ & 0.755 & & & \\
\hline Diabetes in donor & 0.955 & $0.459-1.988$ & 0.902 & & & \\
\hline Body mass index in donor & & & 0.503 & & & \\
\hline$<18.5$ & 1 & 1 & & & & \\
\hline $18.5-24$ & 0.732 & $0.330-1.624$ & & & & \\
\hline $25-29$ & 1.025 & $0.436-2.413$ & & & & \\
\hline$\geq 30$ & 0.51 & $0.106-2.455$ & & & & \\
\hline
\end{tabular}

